This is the final peer-reviewed accepted manuscript of:

Katherine A Dafforn, Tim M Glasby, Laura Airoldi, Natalie K Rivero, Mariana Mayer-Pinto, Emma L Johnston (2015). Marine urbanization: an ecological framework for designing multifunctional artificial structures. Frontiers in Ecology and the Environment, Volume13, Issue2, Pages 82-90

The final published version is available online at:

https://doi.org/10.1890/140050

Rights / License:

The terms and conditions for the reuse of this version of the manuscript are specified in the publishing policy. For all terms of use and more information see the publisher's website.

This item was downloaded from IRIS Università di Bologna (https://cris.unibo.it/)

When citing, please refer to the published version. 


\title{
Marine urbanization: an ecological framework for designing multifunctional artificial structures
}

\author{
Katherine A Dafforn ${ }^{1 *}$, Tim M Glasby ${ }^{2}$, Laura Airoldi ${ }^{3,4}$, Natalie K Rivero ${ }^{1}$, Mariana Mayer-Pinto ${ }^{1}$, \\ and Emma L Johnston ${ }^{1}$
}

Underwater cities have long been the subject of science fiction novels and movies, but the "urban sprawl" of artificial structures being developed in marine environments has widespread ecological consequences. The practice of combining ecological principles with the planning, design, and operation of marine artificial structures is gaining in popularity, and examples of successful engineering applications are accumulating. Here we use case studies to explore marine ecological engineering in practice, and introduce a conceptual framework for designing artificial structures with multiple functions. The rate of marine urbanization will almost certainly escalate as "aquatourism" drives the development of underwater accommodations. We show that current and future marine developments could be designed to reduce negative ecological impacts while promoting ecosystem services.

$\mathrm{U}$ rban sprawl is expanding into marine environments with the construction of artificial structures. In areas of Europe, the US, Australia, and Asia, more than $50 \%$ of the shoreline is now modified by hard engineering, including groins and breakwaters (man-made coastal defenses positioned along the shore or offshore, respectively) to protect against erosion and wave action in support of recreational boating and other activities. The construction of offshore aquaculture facilities and platforms for oil and gas exploration is also increasing (Figure 1; Dugan et al. 2011). Despite habitat loss associated with marine urban sprawl (Airoldi and Beck 2007), the ecological consequences of (Bulleri and Chapman 2010) and mitigation strategies for (eg Browne and Chapman 2011) such structures have only recently been reviewed and attempted. The development of marine

\section{In a nutshell:}

- Marine urbanization is increasing

- The impacts of artificial structures are widely documented, but mitigation strategies are still in development

- Designing marine infrastructure with many purposes could improve provision of ecosystem functions and reduce adverse ecological impacts

\footnotetext{
${ }^{1}$ Evolution and Ecology Research Centre, School of Biological, Earth and Environmental Sciences, University of New South Wales, Sydney, Australia*(k.dafforn@unsw.edu.au); ${ }^{2}$ Port Stephens Fisheries Centre, New South Wales Department of Primary Industries, Port Stephens, Australia; ${ }^{3}$ Dipartimento di Scienze Biologiche, Geologiche e Ambientali, University of Bologna, Bologna, Italy; ${ }^{4}$ Hopkins Marine Station, Stanford University, Pacific Grove, CA
}

infrastructure will continue and most likely escalate in the future, given the need for improved defenses around ports, harbors, and coastal cities as protection from both rising sea levels and increasingly severe coastal storms and flooding (Asif and Muneer 2007). In addition, there are growing demands for coastal urban development, aquaculture facilities, and offshore energy infrastructure (Asif and Muneer 2007).

Human uses of marine environments have modified the global seascape and ecosystem functions (Dugan et al. 2011). "Ecological engineering" - the incorporation of ecological goals and principles into the design of marine artificial structures (Bergen et al. 2001) - can help limit the decline of marine species and degradation of habitats, maintain vital ecosystem services, and ensure more efficient use of natural resources. Here we review selected research on ecological engineering in the marine environment. A systematic review was not possible given that much of the relevant literature crosses scholarly disciplines and is located in books, conference proceedings, and gray literature that would not have appeared in searches. Our review introduces a conceptual framework, together with supporting case studies, for the design of structures that both minimize adverse ecological impacts and provide multiple ecosystem functions.

\section{Ecological consequences of marine urban sprawl}

Artificial structures have local and regional effects on marine ecosystems (Govaerts and Lauwaert 2009; Bulleri and Chapman 2010; Dugan et al. 2011). Here we briefly examine four major types of impact: (1) direct physical disturbance, (2) addition of artificial habitat, (3) indirect physical disturbance, and (4) noise and light pollution. 

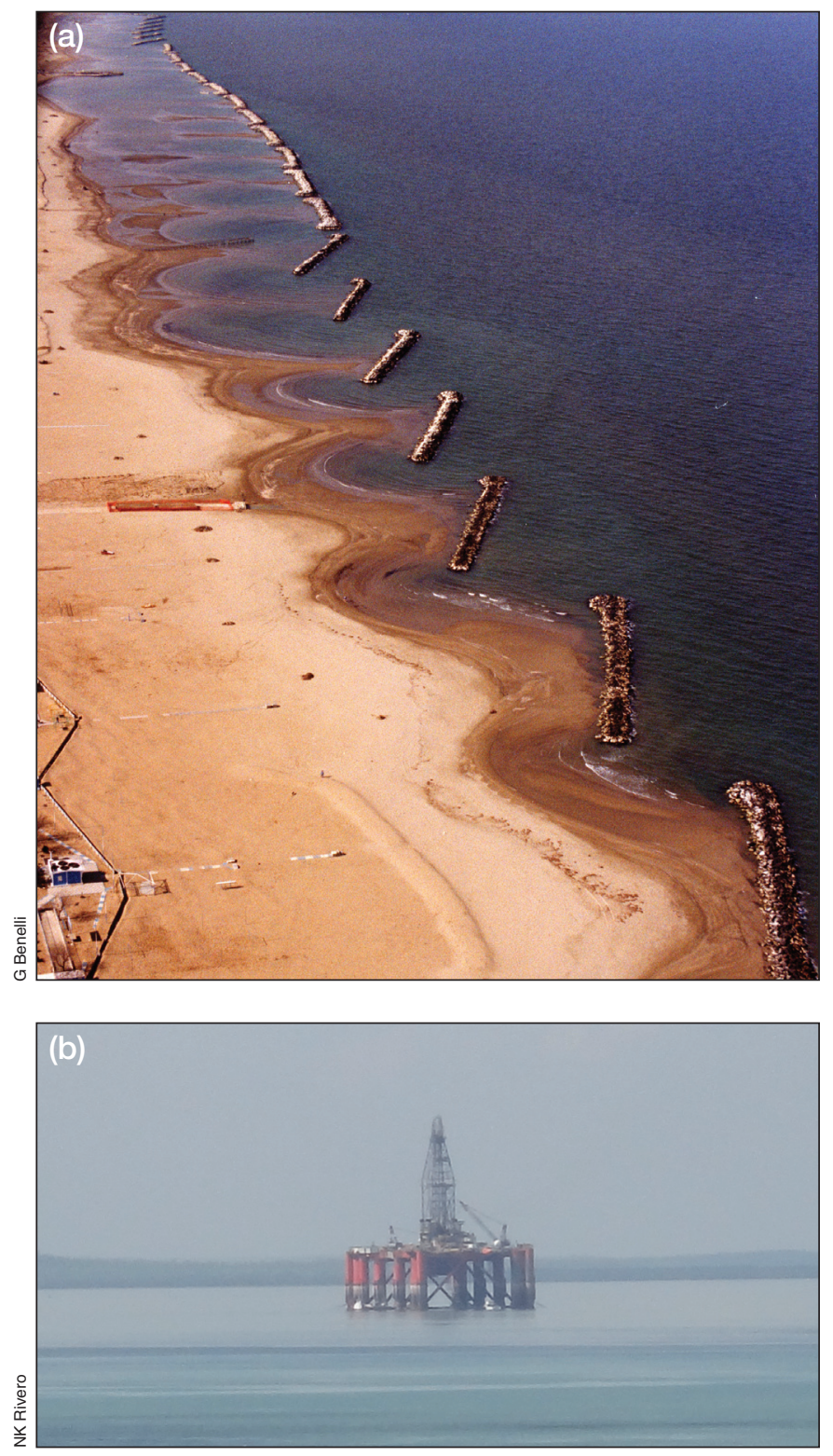

We explore how these impacts relate to different engineering stages (construction, operation, and decommissioning; Figure 2) at local and regional scales, to help identify ecological engineering options.

\section{Local-scale effects}

Physical disturbances arise from the addition or removal of artificial materials during construction and decommissioning, respectively (Figure 2). Recipient native habitats are often damaged or destroyed, and associated assemblages lost (eg up to 70\% of coastlines have been modified globally; WebTable 1a). Offshore, about $12.5 \mathrm{~m}^{2}$ of seabed can be lost in the footprint of a 4-m-diameter turbine with a $10-\mathrm{m}$ base to protect it from sediment abrasion (Wilson and Elliott 2009), contributing to a projected loss in the UK of up to $8600 \mathrm{~km}^{2}$ of seabed by 2020 from offshore wind developments (WebTable 1b). Dredging during construction can displace between 1539
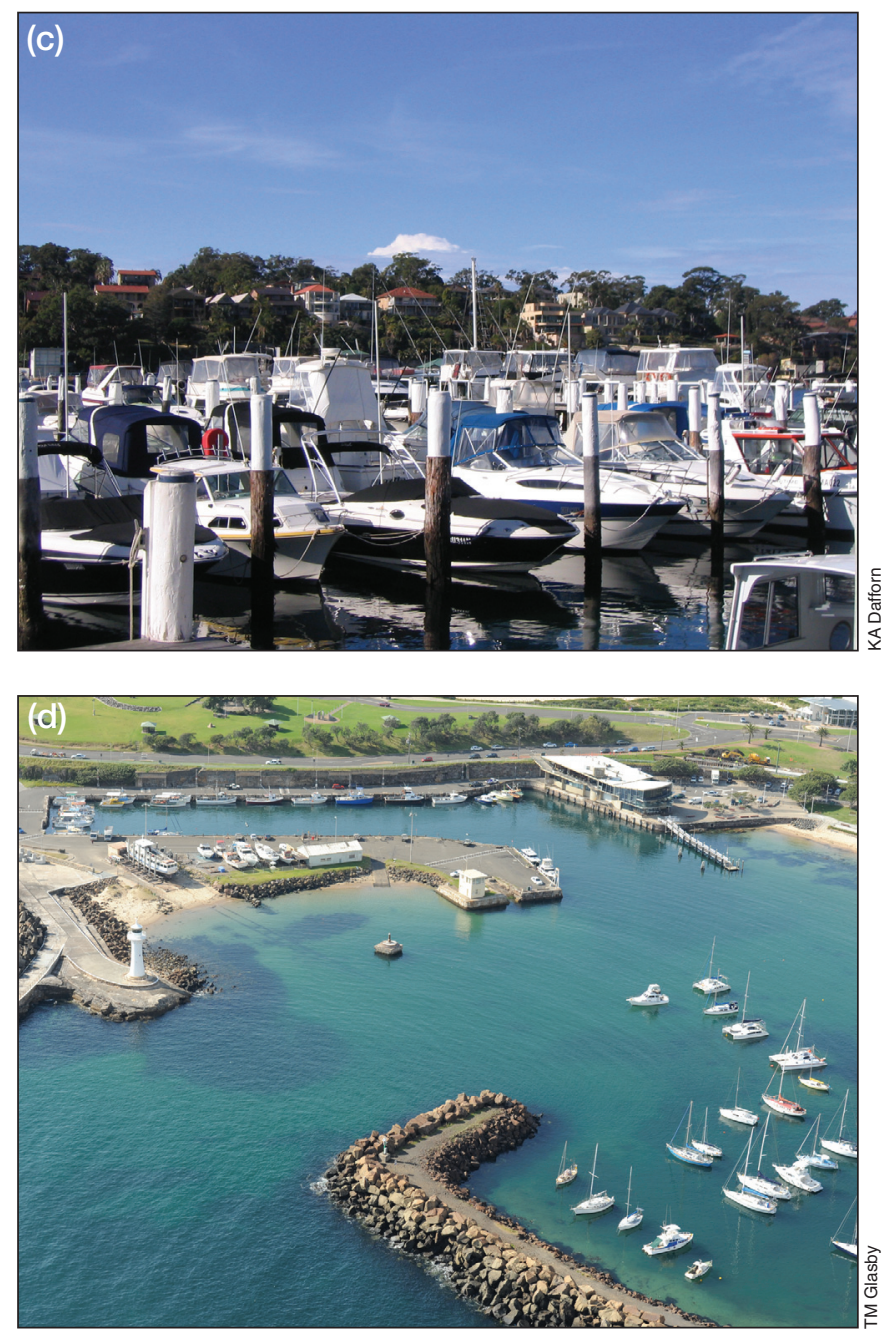

Figure 1. (a) Coastal defense structures in the North Adriatic; (b) an offshore oil platform near Darwin, Australia; (c) a 74berth marina with a network of pilings and pontoons; and $(d)$ an aerial view of Wollongong Harbour, Australia, enclosed by artificial breakwaters.

and $2356 \mathrm{~m}^{3}$ of sediment per turbine into the water column (WebTable 1b) and the removal of underwater scaffolding increases turbidity, which can negatively affect marine plants and animals (Gill 2005). During their operation, artificial structures can alter water flow and sediment deposition, with subsequent effects on benthic species assemblages and productivity (Coates et al. 2014). Constructing marinas surrounded by breakwaters can increase turbidity and reduce flow by up to $30 \%$ (WebTable 1c).

The materials added during construction change the type of resources available, for example by altering the proportion of sheltered, shaded, vertical, and floating surfaces (Figures 1 and 2). Both the orientation of exposed defense structures (either seaward or landward) and the surface texture of construction materials can influence the colonization and recruitment of marine organisms; for instance, barnacles and limpets favor colonization on landward- and seaward-facing structures, respectively 


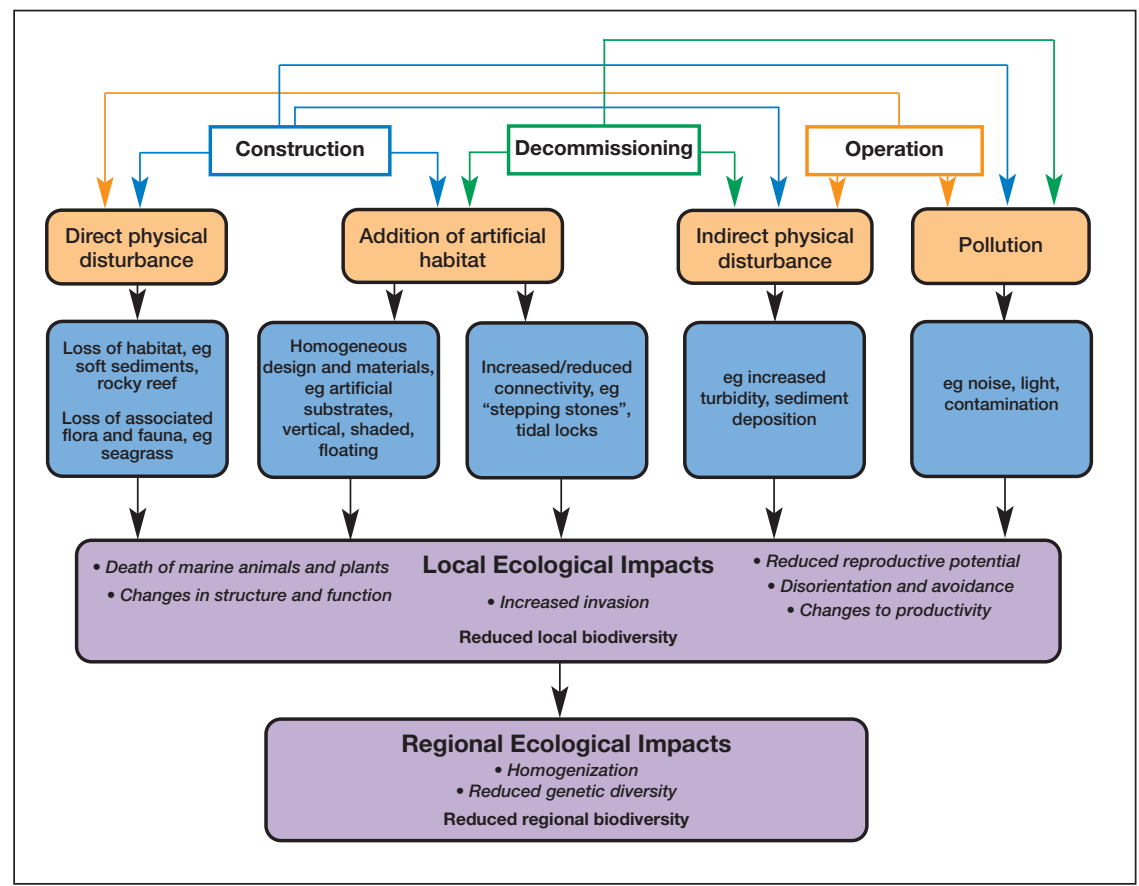

Figure 2. Three engineering phases (construction, operation, and decommissioning) that result in habitat modification (orange boxes). Examples of the physical/chemical changes are described (blue boxes) and potential ecological impacts identified at the local and regional scale (purple boxes).

(Moschella et al. 2005; Coombes et al. 2009). These structures (among others) support assemblages that are distinct from those found in natural reef habitat (Moschella et al. 2005; Bulleri and Chapman 2010). They may also harbor non-indigenous species, which have been found to occupy up to $80 \%$ more space on pilings or pontoons as compared with natural reefs (WebTable 1c; Dafforn et al. 2012). The physical design of artificial structures therefore has major consequences at multiple trophic levels and across seascapes.

During all engineering stages, activities associated with boating and energy extraction can act as sources of various types of pollution (Figure 2). These include artificial light from offshore platforms (Depledge et al. 2010), noise and vibration during wind farm operation (Gill 2005), and contamination around vessel berths (Dafforn et al. 2009a). Night lighting and operational lights on offshore structures can disorient birds and lead to elevated mortality among migratory species (WebTable 1b). The noise and vibrations from construction-related pile driving can reach levels that increase mortality in fish eggs and embryos by $25 \%$ and $85 \%$, respectively, and are associated with disorientation and eardrum rupture in marine mammals (WebTable $1 b$ ). Estuarine infrastructure sites such as marinas are often hotspots of contamination from antifouling paints. Copper and lead concentrations in sediments were 30-80\% higher inside a semi-enclosed marina than outside (WebTable 1c); this finding has been linked to the facilitation of invasions by non-indigenous species (Piola et al. 2009).

\section{Regional-scale effects}

Although marine urbanization is a global issue, scientists lack a comprehensive understanding of the regional ecological consequences of its associated habitat loss and changes in connectivity (Airoldi and Beck 2007). The homogeneity of design and construction materials is a driving force behind the establishment of a suite of fouling species that dominate artificial structures in harbors and coastal areas throughout the world (Figure 2; Dafforn et al. 2009a; Piola et al. 2009). This is analogous to terrestrial urbanization, where use of similar construction materials between cities has been implicated in the spread of non-indigenous species and increasing global biotic homogeneity (McKinney 2006). Similarly, the popularity of pontoons has created shallow, floating stepping-stones for non-indigenous fouling species (Dafforn et al. 2009b) in most human-modified estuaries worldwide (WebTable 1c). Offshore platforms also facilitate the establishment of non-indigenous species, with $11 \%$ of species observed on oil platforms off the Brazilian coast classified as exotic (WebTable 1b).

Urbanization can also result in habitat fragmentation and changes to regional connectivity (Fischer and Lindenmayer 2007). On land, roads, large property developments, and cities create barriers to, or corridors for, invasive species dispersal (Brown et al. 2006). Similarly, the construction of coastal and offshore infrastructure and related changes to water flow can either restrict or facilitate the movement of marine larvae and nutrients (Floerl and Inglis 2003). In the north Adriatic Sea, for example, more than $190 \mathrm{~km}$ of breakwaters, groins, seawalls, and jetties has increased the prevalence of rocky substrates in a predominantly sedimentary environment, facilitating the regional spread of invasive species that require hard surfaces for dispersal and recruitment (WebTable 1a).

\section{Defining multifunctional targets for ecological engineering}

Successful developments in terrestrial urban ecology and artificial reef design demonstrate that artificial structures can be designed to provide both physical infrastructure and critical services (Gaston et al. 2013), including habitat provision, pollution abatement, and facilities for human recreation, education, and food production (Figure 3). 


\section{Lessons from terrestrial urban design}

The design of buildings and spaces in terrestrial systems has improved with increased understanding of the multiple purposes that urban areas can serve. "Green" roofs and walls - plant assemblages established on the tops and sides of buildings - reduce noise and heat loss by absorbing more sound and thermal energy than would a hard surface (Rowe 2011). Green infrastructure may reduce air pollution by up to $37 \%$ and trap 60-79\% of annual stormwater (see WebTable 2a for references). These structures can be intentionally seeded with target organisms to create habitat for native plants (Kadas 2006), including rare and endangered species (WebTable 2a). While some terrestrial functions (eg sound absorption) may not translate well to the marine environment due to differences in the physical properties of air and water, other functions (eg pollution mitigation) have useful analogs, particularly in estuaries.

\section{Lessons from artificial reef design}

The principles of artificial reef creation have been reviewed elsewhere (eg Baine 2001); below, we highlight some examples of the many purposes now incorporated into their design. Artificial reefs are designed for the benefit of target species (Baine 2001) but may also offset habitat loss by restoring degraded ecosystems or mitigate the impacts of tourism on natural reefs by providing attractive alternative sites for recreational diving (Feary et al. 2011). Proposals for decommissioned marine infrastructure to remain in place as reefs are becoming common, and are supported by evidence indicating that such structures can provide important habitat while avoiding the disturbances associated with decommissioning (Macreadie et al. 2011). This strategy will likely require careful management because structures that are simply "abandoned" may become havens for non-indigenous species (Ferreira et al. 2006) or act as a source of contamination (Macreadie et al. 2011).

\section{Multifunctional targets for engineers}

Marine artificial structures are primarily designed for physical protection of infrastructure. Only recently have designs begun to incorporate environmental, social, and economic functions (Chapman and Underwood 2011). As research in this field progresses, the efficacy of designs for multifunctional structures could be examined with a systematic review and meta-analysis. Here we consider seven goals for marine ecological engineering (Figure 2) and identify selected examples of practical designs that can help to achieve these goals (WebPanel 1).

\section{Maintaining local native biota}

Biodiversity is generally thought to enhance ecosystem stability (McCann 2000). Marine artificial structures, particularly seawalls, are now often designed to support biodiversity (eg Chapman and Blockley 2009), but it is important to define what kind of biodiversity to target and why. Increases in biodiversity may actually be a result of the recruitment of undesirable, non-indigenous species rather than native assemblages (Glasby et al. 2007). Furthermore, if natural conditions support diverse sediment communities, then designing structures to enhance rocky reef habitat rather than restoring or providing sedimentary habitat may not be appropriate. Designs that minimize changes to the environment and mimic natural habitats could help support the maintenance of native biota without facilitating invasion.

Urban development has traditionally incorporated materials and designs that create novel conditions. Engineers are now investigating the use of features and materials not only to improve the durability of seawalls and breakwaters but also to more closely resemble historical conditions (Coombes et al. 2013; Firth et al. 2014b). For instance, intertidal seaweeds provide a canopy that reduces temperatures by up to $25 \%$ and creates a stable microclimate, which minimizes weathering and reduces ecological stress for intertidal organisms (Coombes et al. 2013). Observed increases in invertebrate abundance and species richness have been associated with more complex artificial structures that provide refugia (eg crevices; see Table 1 for examples and corresponding references). Similarly, different synthetic materials can influence the 
development of species assemblages (Grozea and Walker 2009). However, caution is required when modifying designs to maintain habitats. In a misguided effort to restore the habitat of an imperiled terrestrial lizard population, increasing structural complexity, rather than mimicking natural conditions, resulted in increased lizard mortality through predation (Hawlena et al. 2010). Careful measurements of substrate types and extent of various physical crevices, as well as the presence of native propagules, would be necessary to truly mimic natural conditions and ensure recruitment of native species.

\section{Restoring local biodiversity}

Restoration of local biodiversity could be facilitated by a shift from adding artificial defense structures to rebuilding natural coastal protection (WebTable $2 \mathrm{~b}$ ). In addition to providing habitat for native species, these natural habitats dissipate wave and storm energy and capture terrestrial runoff (Arkema et al. 2013; Ferrario et al. 2014). Studies in the US and Europe have demonstrated the potential for freshwater wetlands to remove up to $68 \%$ of nitrates and $43 \%$ of phosphates from agricultural runoff, and salt marsh sediments can reduce metal concentrations in runoff by 50\% (WebTable 2b). Also, managed retreat, where hard engineering structures are replaced by natural habitats that provide physical protection, is a feature of the recently developed Seattle Olympic Sculpture Park. Here, seawalls have been removed from a foreshore development and sediments restored to create a small beach that supports migrating salmon (WebTable 2b). This strategy has the added advantage of providing a recreational amenity.

Where economic and social constraints make coastal retreat difficult, other opportunities for restoration of biodiversity can be considered. Structures that provide a potential analog of a native system could support populations of threatened species. Breakwaters and offshore platforms could therefore be intentionally "seeded" with native algae or oysters to restore or boost existing populations (PerkolFinkel et al. 2012) and "cultivated" to maintain specific native populations (Firth et al. 2014b). Survival rates for a threatened species of algae were improved by more than $30 \%$ through recent experimental transplants on European breakwaters (WebTable 2d). This outcome would be doubly effective if the transplanted species also helped to inhibit colonization by unwanted species (eg use of macroalgae to prevent colonization by non-indigenous invertebrates; Dafforn et al. 2012). Experimental seeding of surfaces with algal assemblages can reduce populations of introduced invertebrates by up to $33 \%$ (WebTable 2d). Supplementing formerly "lost" natural habitat such as intertidal rock pools increases biodiversity and density of algae and invertebrates (Browne and Chapman 2014; Firth et al. 2014a). Purposefully installed to protect recreational swimmers at coastal locations in Australia, artificial nets also serve as important habitat for seahorses, the populations of which have suffered from degradation of natural habitat such as kelp beds (WebTable 2e). These studies suggest that marine restoration research could offer useful insights for marine urban design aiming to restore underwater biodiversity.

\section{Maintaining regional biodiversity}

The spatial distribution of coastal defense structures, boating facilities, and offshore aquaculture facilities and platforms affects connectivity (WebTable 1a) and therefore biodiversity at a regional scale. While increased connectivity could provide new dispersal routes to facilitate species migrations in response to climate change (Travis et al. 2013), there may be drawbacks related to the rapid expansion of "weedy" nonindigenous species, which are often better able to colonize artificial structures than are native species.

Marine urban developments designed to reduce connectivity could maintain regional biodiversity by restricting the spread of invasive species. Given that they are sited in sheltered, low-flow environments, ports and marinas are often heavily invaded and fouled due to the inflow of propagules (invertebrate larvae and algal spores) and nutrients (Floerl and Inglis 2003; Johnston et al. 2011). Breakwaters or tidal locks often contain these populations (WebTable 2f), but propagules can also spread via stormwater or ships. Management strategies such as regular cleaning and regulations to reduce biofouling are therefore required in such areas. However, antifouling strategies sometimes rely on toxic metal biocides, which promote non-indigenous species over native ones; this could be prevented through improved flushing and the use of non-toxic compounds (Piola et al. 2009; Dafforn et al. 2011).

\section{Providing educational and recreational opportunities}

Marine artificial structures - including decommissioned offshore oil and gas platforms - may provide educational and recreational opportunities (eg adaptive reuse; WebTable 2c) at different stages of their lifecycle. We previously highlighted the foreshore development in Seattle's Olympic Sculpture Park, where habitat restoration facilitated the provision of recreational services (see WebPanel 1 for related examples). During their operation, oil rigs and their environs are similar in part to marine protected areas due to restrictions on fishing and vessel traffic (Inger et al. 2009). Adaptive reuse of the foundations of these structures after decommissioning might therefore include recreational dive sites. Plans have already been developed to enclose a decommissioned oil platform and stock the surrounding vicinity with deep-water fish, initially for fisheries research purposes but ultimately for commercial aquaculture (James and Slaski 2006). Because many of these structures have been in place for 30-40 years, their re-purposing could avoid the adverse ecological impacts associated with their removal.

\section{Maintaining water quality}

Pollution abatement is often incorporated into terrestrial urban design (Gaston et al. 2013). In marine systems, preserving or improving water quality promotes ecosystem 
functioning. Apart from supporting a wide range of species and providing an opportunity to improve local water-quality conditions, habitats such as wetlands and salt marshes also provide low-maintenance coastal protection.

Engineering-based solutions such as physical containment (WebTable 2f) may be required to reduce pollutant contamination at boating infrastructure sites (eg marinas). However, improvements in water quality could also be achieved through biological means, by seeding structures with organisms that absorb inorganic contaminants (eg seaweed) or remove organic particles (eg suspension/deposit feeders; Gifford et al. 2005). Studies have highlighted the potential for bivalves (eg oysters) to reduce levels of nitrogen and phosphorus in effluent from shrimp aquaculture by $72 \%$ and $86 \%$, respectively, although the oysters could not then be harvested for human consumption (WebTable 2d). The choice of the target species may be improved by assessment of the local ecological conditions. Most artificial surfaces tend to be vertical or heavily shaded; thus, seeding these structures with a photosynthetic organism would require further measures, such as adding openings or "skylights" to reduce shading (see WebPanel 1).

\section{Facilitating carbon storage}

Increased atmospheric concentrations of greenhouse gases and associated climate change are driving research

\section{Table 1. Examples of ecological engineering of coastal infrastructure to increase hard substrate diversity}

\begin{tabular}{llll}
\hline \multicolumn{1}{c}{ Location } & Engineering & Results & References \\
\hline $\begin{array}{l}\text { Increase sloping intertidal habitat } \\
\text { White Bay, Australia }\end{array}$ & $\begin{array}{l}\text { Added a sloping wall of small blocks } \\
\text { to seawall }\end{array}$ & $\begin{array}{l}\text { No increase in biodiversity: reduced } \\
\text { sessile invertebrate cover, and fewer } \\
\text { mobile species on horizontal than } \\
\text { vertical surfaces }\end{array}$ & $\begin{array}{l}\text { Chapman and } \\
\text { Underwood (20II) }\end{array}$ \\
$\begin{array}{l}\text { Quakers Hat Bay, } \\
\text { Australia }\end{array}$ & $\begin{array}{l}\text { Added a sloping wall of boulders to } \\
\text { seawall }\end{array}$ & No increase in biodiversity & Chapman and \\
\hline
\end{tabular}

Increase complexity of seawall

Azores Is, Portugal Drilled pits of various sizes and densities

Farm Cove, Australia Added holes and grooves to seawall

Kirribilli, Australia Surveyed crevices between blocks

Kirribilli, Australia Added crevices between blocks

West Sussex, UK Added pits (large and/or small) to seawall

Plymouth, UK Added pits (large/small) to seawall

Shaldon, UK Added grooves, pits, and recessed crevices

\begin{tabular}{|c|c|}
\hline $\begin{array}{l}\text { Add additional habitat } \\
\text { Rose Bay, Australia }\end{array}$ & Added cavity \\
\hline $\begin{array}{l}\text { McMahons Pt, } \\
\text { Australia }\end{array}$ & Added cavity and lip to form pool \\
\hline Tywyn, UK & $\begin{array}{l}\text { Added artificial tide pools with two } \\
\text { depths to breakwater }\end{array}$ \\
\hline Colwyn Bay, UK & $\begin{array}{l}\text { Added Bioblock unit (tide pools, } \\
\text { crevices, pits) to breakwater }\end{array}$ \\
\hline
\end{tabular}

Up to 10 times as many mobile limpets Martins et al. (20I0) in quadrats with pits, due to immigration and recruitment

Increased densities of limpets in grooves compared to holes and background; lower densities of chitons in large holes than in grooves

Increased densities of chitons in crevices (77-100\%) than on exposed surfaces $(0-23 \%)$

Increased taxonomic richness of algae and sessile invertebrates in crevices than on exposed surfaces

Increased abundances of barnacles in small crevices and rough compared to smooth surfaces; increased diversity with greater complexity

$60 \%$ of functional groups unique to drilled pits; improved species richness in pits

Barnacles unique to recesses

Chapman and

Underwood (20II)

Moreira et al. (2007)

Dugan et al. (20II)

Moschella et al. (2005)

Firth et al. (20I4b)

Firth et al. (20I4b)

Rapid colonization by mobile tide pool species

Chapman and Underwood (20II)

Increased diversity of foliose algae and sessile and mobile animals; more

Chapman and species in constructed pools than in nearby natural pools

Blockley (2009)

$30 \%$ more species in shallow pools than Firth et al. (20l4b) on projections

$60 \%$ more species on Bioblock than on Firth et al. (2014b) adjacent rocks 


\section{Panel 1. Urbanization of the ocean}

Global interest in diving tourism has driven the design of floating and submarine accommodation and restaurants; this submerged tourism or "aquatourism" is a developing industry (Bitterman 2013). Between the 1960s and 1970s, few of these designs had been completed due to technical issues and other constraints (Kaji-O'Grady and Raisbeck 2005). More recent operational examples of underwater accommodation include the Jules' Undersea Lodge in Florida and Utter Inn in Sweden, each designed for fewer than 10 guests. These represent relatively small structures as compared with the proposed Poseidon Undersea Resort in Fiji (20 suites) and the Hydropolis Undersea Resort in Dubai (220 suites; Bitterman 2013). The architects of these designs have highlighted the potential for the structures to provide both recreational (tourism) and educational (marine research) services (Bitterman 20I3).

On a larger scale, there is increasing interest in developing larger floating and submerged cities and underwater solutions to overcrowding (Figure 4; Kaji-O'Grady and Raisbeck 2005). These designs may not be realized in the near future, but the potential ecological impacts from the addition of these hard substrates to the marine environment should still be considered, even at this conceptual stage (Figure 2; Naylor et al. 20I2), together with other opportunities for the provision of ecosystem services, particularly the maintenance or restoration of biodiversity (Figure 3).
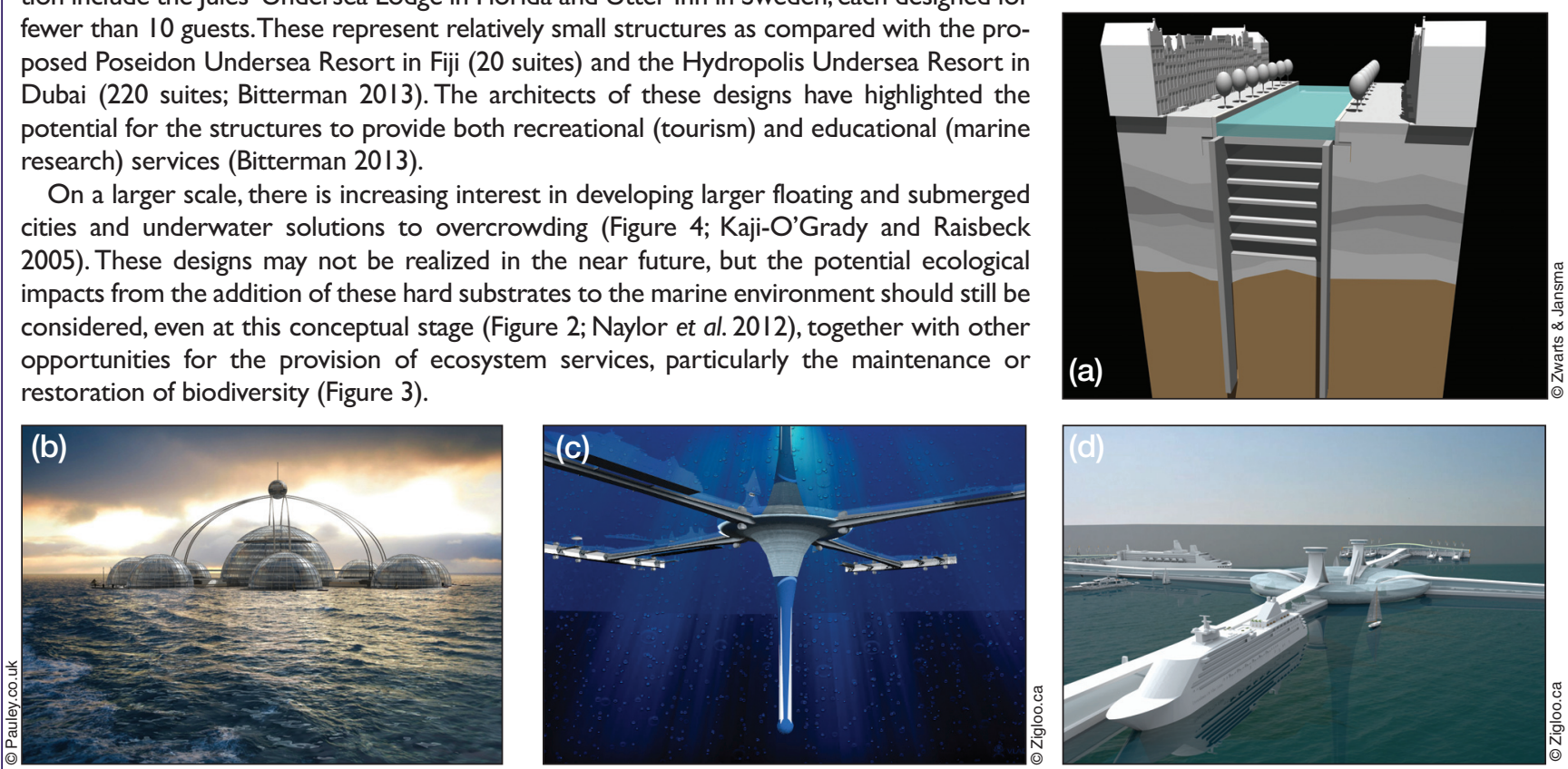

Figure 4. (a) Amsterdam's plans to utilize subterranean car parking under the city's canal network; (b) the Sub Biosphere is a selfsustainable city for 100 inhabitants that presents recreational and educational opportunities; (c) and (d) views from below and above the Gyre "seascraper", which is intended to provide accommodation and berthing for passenger vessels (Panel 1).

toward biological solutions for carbon $(\mathrm{C})$ sequestration and storage (Perring et al. 2013). Terrestrial vegetation sequesters carbon dioxide $\left(\mathrm{CO}_{2}\right)$ and increases $\mathrm{C}$ storage above- and belowground (Perring et al. 2013), as do marine seagrasses (Lavery et al. 2013). Long-lived species of seagrass (eg Posidonia spp) are likely to have the greatest capacity to store C (Fourqurean et al. 2012), yet are also the most difficult species to rehabilitate. Therefore, using seagrasses to enhance $\mathrm{C}$ capture may currently be unrealistic (Irving et al. 2011). Bioengineered oyster reefs have been proposed for both shoreline protection and C storage (Dehon 2010); however, this option requires further investigation because in some cases the $\mathrm{CO}_{2}$ produced by oysters during shell construction exceeds the potential for sequestration. Seaweeds have the capacity for major C storage through biomass accumulation, which pilot studies in South Korea have estimated at around $10 \mathrm{t} \mathrm{CO}_{2} \mathrm{ha}^{-1} \mathrm{yr}^{-1}$ (WebTable 2d). Marine sediments also have the ability to store $\mathrm{CO}_{2}$ (Schrag 2009), but transport logistics prevent the practical realization of this solution (Golomb 1993). Existing pipelines associated with decommissioned infrastructure may be used to transport $\mathrm{CO}_{2}$ to deep-sea sediments for storage (Seevam et al. 2010). Although potentially feasible, large-scale enrichment of marine sediments requires further scrutiny, given that the ecological consequences are not yet fully understood.

\section{Supporting aquaculture and food production}

The potential for artificial reefs to support fish populations and food production has been reviewed elsewhere (Feary et al. 2011). Therefore we focus here on the opportunities to design offshore platforms (eg wind farms) and coastal infrastructure (eg breakwaters) that support aquaculture such as seaweed and shellfish.

For several decades, aquaculture has included offshore operations because many farmed species are unsuitable for land-based ponds or tanks. Relocating aquaculture to offshore sites reduces the risk of anoxia and disease because the offshore movement of water rapidly disperses nutrient-rich animal waste and promotes oxygenation (Buck et al. 2004). These ventures are costly and there are already plans to culture multiple species, including mussels, oysters, and seaweed. Since energy-harnessing structures such as wind turbines and oil platforms are effectively built on foundations similar to artificial reefs, these may create cost-effective opportunities for offshore aquaculture by providing anchor points in high-energy environments (Buck et al. 2004). While operational, these structures can incorporate the needs of different stakeholders, which will help to spread the financial costs (Buck et al. 2004).

Coastal environments are replete with defense structures such as breakwaters, which may be another option 
for aquaculture development. Seeding of structures with the commercially important Pacific oyster (Crassostrea gigas) has the potential to improve water quality through filtration while providing an economic return (Forrest et al. 2009). Such projects require careful analysis to target appropriate native species and avoid negative ecological outcomes (eg the unintentional transfer of non-indigenous species) that might negate any benefits.

\section{Conclusions}

The urbanization of the oceans is likely to increase (Panel 1 ), and while the design of artificial structures remains linked solely to engineering goals, their multifunctional potential may not be fulfilled. We have highlighted opportunities to incorporate multiple targets into designs: a conceptual framework that could underpin future policy. In Europe, there are legal frameworks to support biodiversity enhancements on marine developments; for instance, the European Convention on Biological Diversity integrates biodiversity into all planning processes (Naylor et al. 2012). However, key coastal policies in other countries lack the same specificity; for example, the Australian Coastal Protection Act 1979 requires ecologically sustainable development but does not specifically require habitat enhancements or the application of ecological engineering. Similarly, the US Coastal Zone Management Act of 1972 requires that coastal and estuarine areas be managed to restore or enhance ecological function, but fails to address the management of artificial structures. We suggest that biodiversity enhancement and other multifunctional goals (eg pollution mitigation) could be incorporated into policy. Marine structures need not be designed solely for purposes such as coastal protection but can incorporate essential ecological, social, and provisioning services while minimizing adverse environmental impacts. Developing policies that require multifunctional targets to be identified during planning stages could drive this important change in future marine urbanization.

\section{Acknowledgements}

This research was primarily supported by the Australian Research Council through a Linkage Grant awarded to KAD, TMG, LA, and ELJ. LA was supported by a Fulbright Scholarship; MMP and NKR received research support from UNSW. This is SIMS Publication \# 141.

\section{References}

Airoldi L and Beck MW. 2007. Loss, status and trends for coastal marine habitats of Europe. In: Gibson RN, Atkinson RJA, and Gordon JDM (Eds). Oceanography and marine biology: an annual review, vol 45. London, UK: CRC Press.

Arkema KK, Guannel G, Verutes G, et al. 2013. Coastal habitats shield people and property from sea-level rise and storms. Nature Climate Change 3: 913-18.

Asif M and Muneer T. 2007. Energy supply, its demand and security issues for developed and emerging economies. Renew Sust Energ Rev 11: 1388-413.

Baine M. 2001. Artificial reefs: a review of their design, application, management and performance. Ocean Coast Manage 44: 241-59.

Bergen SD, Bolton SM, and Fridley JL. 2001. Design principles for ecological engineering. Ecol Eng 18: 201-10.

Bitterman N. 2013. "Aquatourism": submerged tourism, a developing area. Curr Iss Tour 17: 1-11.

Brown GP, Phillips BL, Webb JK, and Shine R. 2006. Toad on the road: use of roads as dispersal corridors by cane toads (Bufo marinus) at an invasion front in tropical Australia. Biol Conserv 133: 88-94.

Browne MA and Chapman MG. 2011. Ecologically informed engineering reduces loss of intertidal biodiversity on artificial shorelines. Environ Sci Technol 45: 8204-07.

Browne M and Chapman M. 2014. Mitigating against the loss of species by adding artificial intertidal pools to existing seawalls. Mar Ecol-Prog Ser 497: 119-29.

Buck BH, Krause G, and Rosenthal H. 2004. Extensive open ocean aquaculture development within wind farms in Germany: the prospect of offshore co-management and legal constraints. Ocean Coast Manage 47: 95-122.

Bulleri F and Chapman MG. 2010. The introduction of coastal infrastructures as a driver of change in marine environments. $J$ Appl Ecol 47: 26-35.

Chapman MG and Blockley DJ. 2009. Engineering novel habitats on urban infrastructure to increase intertidal biodiversity. Oecologia 161: 625-35.

Chapman MG and Underwood AJ. 2011. Evaluation of ecological engineering of "armoured" shorelines to improve their value as habitat. J Exp Mar Biol Ecol 400: 302-13.

Coates DA, Deschutter Y, Vincx M, and Vanaverbeke J. 2014. Enrichment and shifts in macrobenthic assemblages in an offshore wind farm area in the Belgian part of the North Sea. Mar Environ Res 95: 1-12.

Coombes MA, Naylor LA, Roast SD, and Thompson RC. 2009. Coastal defences and biodiversity: the influence of material choice and small-scale surface texture on biological outcomes. In: Allsop W (Ed). Coasts, marine structures and breakwaters. London, UK: Thomas Telford.

Coombes MA, Naylor LA, Viles HA, and Thompson RC. 2013. Bioprotection and disturbance: seaweed, microclimatic stability and conditions for mechanical weathering in the intertidal zone. Geomorphology 202: 4-14.

Dafforn KA, Glasby TM, and Johnston EL. 2009a. Links between estuarine condition and spatial distributions of marine invaders. Divers Distrib 15: 807-21.

Dafforn KA, Glasby TM, and Johnston EL. 2012. Comparing the invasibility of experimental "reefs" with field observations of natural reefs and artificial structures. PLoS ONE 7: e38124.

Dafforn KA, Johnston EL, and Glasby TM. 2009b. Shallow moving structures promote marine invader dominance. Biofouling 25: $277-87$.

Dafforn KA, Lewis JA, and Johnston EL. 2011. Antifouling strategies: history and regulation, ecological impacts and mitigation. Mar Pollut Bull 62: 453-65.

Dehon DD. 2010. Investigating the use of bioengineered oyster reefs as a method of shoreline protection and carbon storage (MS thesis). Baton Rouge, LA: Louisiana State University.

Depledge MH, Godard-Codding CAJ, and Bowen RE. 2010. Light pollution in the sea. Mar Pollut Bull 60: 1383-85.

Dugan JE, Airoldi L, Chapman MG, et al. 2011. Estuarine and coastal structures: environmental effects, a focus on shore and nearshore structures. In: Wolanski E and McLusky D (Eds). Treatise on estuarine and coastal science. Waltham, MA: Academic Press.

Feary DA, Burt JA, and Bartholomew A. 2011. Artificial marine 
habitats in the Arabian Gulf: review of current use, benefits and management implications. Ocean Coast Manage 54: $742-49$.

Ferrario F, Beck MW, Storlazzi CD, et al. 2014. The effectiveness of coral reefs for coastal hazard risk reduction and adaptation. Nat Comm 5: art3794.

Ferreira CEL, Gonçalves JEA, and Coutinho R. 2006. Ship hulls and oil platforms as potential vectors to marine species introduction. J Coastal Res SI 39: 1340-45.

Firth LB, Schofield M, White FJ, et al. 2014a. Biodiversity in intertidal rock pools: informing engineering criteria for artificial habitat enhancement in the built environment. Mar Environ Res; doi:10.1016/j.marenvres.2014.03.016.

Firth LB, Thompson RC, Abbiat M, et al. 2014b. Between a rock and a hard place: environmental and engineering considerations when designing coastal defence structures. Coast Eng 87: 122-35.

Fischer J and Lindenmayer DB. 2007. Landscape modification and habitat fragmentation: a synthesis. Global Ecol Biogeogr 16: 265-80.

Floerl $\mathrm{O}$ and Inglis GJ. 2003. Boat harbour design can exacerbate hull fouling. Austral Ecol 28: 116-27.

Forrest BM, Keeley NB, Hopkins GA, et al. 2009. Bivalve aquaculture in estuaries: review and synthesis of oyster cultivation effects. Aquaculture 298: 1-15.

Fourqurean JW, Duarte CM, Kennedy H, et al. 2012. Seagrass ecosystems as a globally significant carbon stock. Nat Geosci 5: 505-09.

Gaston KJ, Ávila-Jiménez ML, and Edmondson JL. 2013. Managing urban ecosystems for goods and services. J Appl Ecol 50: 830-40.

Gifford S, Dunstan H, O'Connor W, and Macfarlane GR. 2005. Quantification of in situ nutrient and heavy metal remediation by a small pearl oyster (Pinctada imbricata) farm at Port Stephens, Australia. Mar Pollut Bull 50: 417-22.

Gill AB. 2005. Offshore renewable energy: ecological implications of generating electricity in the coastal zone. J Appl Ecol 42: $605-15$.

Glasby TM, Connell SD, Holloway MG, and Hewitt CL. 2007. Nonindigenous biota on artificial structures: could habitat creation facilitate biological invasions? Mar Biol 151: 887-95.

Golomb D. 1993. Ocean disposal of $\mathrm{CO}_{2}$ : feasibility, economics and effects. Energ Convers Manage 34: 967-76.

Govaerts A and Lauwaert B. 2009. Assessment of the impact of coastal defence structures. London, UK: OSPAR Commission. Publication number 435/2009.

Grozea CM and Walker GC. 2009. Approaches in designing nontoxic polymer surfaces to deter marine biofouling. Soft Matter 5: 4088-100.

Hawlena D, Saltz D, Abramsky Z, and Bouskila A. 2010. Ecological trap for desert lizards caused by anthropogenic changes in habitat structure that favor predator activity. Conserv Biol 24: 803-09.

Inger R, Attrill MJ, Bearhop S, et al. 2009. Marine renewable energy: potential benefits to biodiversity? An urgent call for research. J Appl Ecol 46: 1145-53.

Irving AD, Connell SD, and Russell BD. 2011. Restoring coastal plants to improve global carbon storage: reaping what we sow. PLoS ONE 6: e18311.
James MA and Slaski R. 2006. Appraisal of the opportunity for offshore aquaculture in UK waters. Scotland, UK: FRM. Report FC0934.

Johnston EL, Marzinelli EM, Wood CA, et al. 2011. Bearing the burden of boat harbours: heavy contaminant and fouling loads in a native habitat-forming alga. Mar Pollut Bull 62: 2137-44.

Kadas G. 2006. Rare invertebrates colonizing green roofs in London. Urban Habit 4: 66-86.

Kaji-O'Grady S and Raisbeck P. 2005. Prototype cities in the sea. $J$ Architecture 10: 443-61.

Lavery PS, Mateo M-Á, Serrano O, and Rozaimi M. 2013. Variability in the carbon storage of seagrass habitats and its implications for global estimates of blue carbon ecosystem service. PLoS ONE 8: e73748.

Macreadie PI, Fowler AM, and Booth DJ. 2011. Rigs-to-reefs: will the deep sea benefit from artificial habitat? Front Ecol Environ 9: 455-61.

Martins GM, Thompson RC, Neto AI, et al. 2010. Enhancing stocks of the exploited limpet Patella candei d'Orbigny via modifications in coastal engineering. Biol Conserv 143: 203-11.

McCann KS. 2000. The diversity-stability debate. Nature 405: 228-33.

McKinney ML. 2006. Urbanization as a major cause of biotic homogenization. Biol Conserv 127: 247-60.

Moreira J, Chapman MG, and Underwood AJ. 2007. Maintenance of chitons on seawalls using crevices on sandstone blocks as habitat in Sydney Harbour, Australia. J Exp Mar Biol Ecol 347: 134-43.

Moschella PS, Abbiati M, Åberg P, et al. 2005. Low-crested coastal defence structures as artificial habitats for marine life: using ecological criteria in design. Coastal Eng 52: 1053-71.

Naylor LA, Coombes MA, Venn O, et al. 2012. Facilitating ecological enhancement of coastal infrastructure: the role of policy, people and planning. Environ Sci Policy 22: 36-46.

Perkol-Finkel S, Ferrario F, Nicotera V, and Airoldi L. 2012. Conservation challenges in urban seascapes: promoting the growth of threatened species on coastal infrastructures. J Appl Ecol 49: 1457-66.

Perring M, Manning P, Hobbs RJ, et al. 2013. Novel urban ecosystems and ecosystem services. In: Hobbs RJ, Higgs ES, and Hall CM (Eds). Novel ecosystems: intervening in the new ecological world order. London, UK: Wiley-Blackwell.

Piola RF, Dafforn KA, and Johnston EL. 2009. The influence of antifouling practices on marine invasions: a mini-review. Biofouling 25: 633-44.

Rowe DB. 2011. Green roofs as a means of pollution abatement. Environ Pollut 159: 2100-10.

Schrag DP. 2009. Storage of carbon dioxide in offshore sediments. Science 325: 1658-59.

Seevam P, Race J, Downie M, et al. 2010. Capturing carbon dioxide: the feasibility of re-using existing pipeline infrastructure to transport anthropogenic $\mathrm{CO}_{2}$. 8th International Pipeline Conference; 27 Sep-1 Oct 2010; Calgary, Canada. New York, NY: American Society of Mechanical Engineers.

Travis JMJ, Delgado M, Bocedi G, et al. 2013. Dispersal and species' responses to climate change. Oikos 122: 1532-40.

Wilson JC and Elliott M. 2009. The habitat-creation potential of offshore wind farms. Wind Energy 12: 203-12. 